\title{
Effect of oral administration of kynurenic acid on the activity of the peripheral blood leukocytes in mice
}

\author{
JOANNA MAEACZEWSKA ${ }^{l}$, ANDRZEJ KRZYSZTOF SIWICKI ${ }^{1}$, ROMAN MARCIN WÓJCIK ${ }^{1}$, \\ EDYTA KACZOREKI, WALDEMAR ANDRZEJ TURSKI
}

${ }^{1}$ Department of Microbiology and Clinical Immunology, Faculty of Veterinary Medicine, University of Warmia and Mazury, Olsztyn, Poland ${ }^{2}$ Department of Experimental and Clinical Pharmacology, Medical University of Lublin, Poland

\begin{abstract}
Kynurenic acid (KYNA), an endogenous tryptophan metabolite, is a selective ligand of the GPR35 receptor, expressed mainly on the immune cells. In inflammatory conditions, by affecting this receptor, KYNA inhibits the synthesis of pro-inflammatory cytokines and probably protects tissues from oxidative damage. However, we lack data regarding the effect of exogenous KYNA on the activity of immune cells in healthy individuals. The objective of this study has been to determine the influence of kynurenic acid administered to mice in different doses $(2.5,25$ or $250 \mathrm{mg} / \mathrm{l})$ and for different time periods $(3,7,14,28$ days) in drinking water, on the activity of their peripheral blood leukocytes. The determinations comprised the proliferative activity of lymphocytes (MTT assay) and the phagocytic activity as well as the respiratory burst activity of granulocytes and monocytes (Phagotest, Phagoburst). It was only the lowest KYNA dose that influenced the mitogenic response of lymphocytes, namely by increasing the proliferation of $T$ cells. The impact on the phagocytic activity was varied with KYNA dose and administration time. However, all the KYNA doses significantly lowered the activity of oxidative burst in phagocytes, which was probably associated with its antioxidant properties. In the light of the research results, kynurenic acid may find applications as an immuno-modulating agent able to correct an excessive or insufficient response of phagocytizing cells, protecting an organism from oxidative stress.
\end{abstract}

Key words: kynurenic acid, proliferative response, oxidative burst, antioxidant properties, phagocytic activity.

(Centr Eur J Immunol 2014; 39 (1): 6-13)

\section{Introduction}

Kynurenic acid (KYNA) is one of the endogenous products of tryptophan metabolism, formed along the kynurenine pathway. This pathway is a link between the immune and the nervous system; it also plays an immunoregulatory role during infections, pregnancies, autoimmunological processes, neoplasm growth and after organ transplantations [1-3]. One of the major enzymes of the kynurenic path such as IDO (indoleamine 2,3-dioxygenase) is expressed mainly in lymphoid organs and the nervous system, and its production grows substantially during inflammations and infections. The most important stimulant of IDO is thought to be interferon $\gamma$ (IFN- $\gamma$ ), released by activated $\mathrm{T}$ lymphocytes and other leukocytes $[4,5]$. Thus, infections in the organism are accompanied by an elevated degradation and IDO-induced depletion of tryptophan, which in turn is linked to the inhibited proliferation of viruses, parasitic protozoa and other pathogens, as well as neoplastic cells $[4,5]$. Besides, some of the tryptophan metabolites produced in the kynurenic pathway (kynurenines) are responsible for the negative feedback in the inflammatory state, and their effect on the activity of $\mathrm{T}$ cells, consisting in the anti-proliferative and pro-apoptotic influences, is of particular importance [3-5].

Moreover, KYNA, being a selective ligand of the GPR35 receptor, is involved in the modulation of the immune response because this receptor is expressed mainly on cells connected with the immune system [2, 3, 6-8]. Under the influence exerted by KYNA on this receptor, the synthesis of pro-inflammatory cytokines [interleukin $1 \alpha$ (IL- $1 \alpha$ ), tumor necrosis factor $\alpha$ (TNF- $\alpha$ ), high mobility group box 1 (HMGB1)], and less often anti-inflammatory ones (IL-4) in different cells is depressed [2, 3, 7-9]. While it is true than a nanomolar concentration of KYNA found in the plasma and tissues of healthy individuals is insufficient to activate GPR35 receptors, in the inflammatory condition, owing to

Correspondence: Joanna Małaczewska, PhD, Department of Microbiology and Clinical Immunology, Faculty of Veterinary Medicine, University of Warmia and Mazury, Oczapowskiego 13, 10-719 Olsztyn, Poland, e-mail: j.malaczewska7@wp.pl 
the activation of IDO, the KYNA concentration rises to micromolar levels, which enable the activation of receptors [3, 8]. Pharmacological modulation of the GPR35 receptor by KYNA may prove to be helpful whenever it is necessary to correct an excessive or inadequate response of the immune reaction of the organism. Besides, the fact that GPR3 receptors are present on the surface of enterocytes of intestinal crypts together with effective absorption of KYNA in the digestive tract $[10,11]$ raises hope that this acid could also be used as a potential dietary supplement. Relatively high levels of KYNA are for example found in beekeeping products and in some herbs, which - alongside the ability of KYNA to affect the immune system - may prove that it is one of the active bodies, responsible for the health-promoting effects of the above products [12].

The available literature is short of reports on the influence of KYNA administered through the alimentary route on the activity of immune cells in healthy animals. This has encouraged us to undertake a study with the aim of determining the effect of KYNA, given to mice in different doses $(2.5,25$ or $250 \mathrm{mg} / \mathrm{l})$ and for different time periods $(3,7,14,28$ days $)$ in drinking water, on the activity of leukocytes in the peripheral blood. The proliferative activity of lymphocytes was assessed in an MTT reduction colorimetric assay while the phagocytic activity and respiratory burst activity of granulocytes and monocytes were analyzed by flow cytometry (Phagotest and Phagoburst kits).

\section{Material and methods}

\section{Mice}

The experiment was performed on 160 male BALB/c mice, aged 10-12 weeks, with body weight of 22-26 g. The animals were maintained on a 12-h light/dark cycle at controlled temperature $\left(20 \pm 1^{\circ} \mathrm{C}\right)$ and supplied with rodent chow and water ad libitum throughout the experiment. Mice were divided randomly into four equal groups: control group (0) not receiving the KYNA, and three experimental groups administered the KYNA (Sigma-Aldrich) solution in drinking water at concentrations of $2.5,25$ or $250 \mathrm{mg} / \mathrm{l}$. After 3, 7, 14 and 28 consecutive days of administration of the KYNA solution, 10 individuals from each group were sacrificed. The animals were anesthetized by inhalation of Aerrane (isoflurane, Baxter Poland) and their blood was collected by heart puncture. Blood collected from five individuals of each group was used for the MTT assay, and from the next five for the flow cytometry. The experiment has been approved by the Local Ethics Committee.

\section{Isolation of leukocytes}

In order to isolate lymphocytes for the MTT test the whole heparinized blood was placed on density gradient Histopaque 1077 (Sigma-Aldrich), and then centrifuged at $400 \mathrm{~g}$ for $30 \mathrm{~min}$ at $20^{\circ} \mathrm{C}$. The interface cells were collected and washed three times with the RPMI-1640 medium at $250 \mathrm{~g}$ for $10 \mathrm{~min}$. Via- bility of isolated cells was evaluated by trypan blue exclusion and was determined to be greater than $95 \%$ in each case. The cells were suspended in RPMI-1640 medium containing 10\% fetal calf serum (Sigma-Aldrich) and $1 \%$ antibiotic-antimycotic solution (Sigma-Aldrich), and dispensed into 96-well plates at a concentration of $2 \times 10^{6}$ cells $\mathrm{ml}^{-1}$. Then, the lymphocytes were cultured at $37^{\circ} \mathrm{C}$ under humidified atmosphere of $5 \% \mathrm{CO}_{2}$ and $95 \%$ air atmosphere and used for the MTT assay.

\section{Proliferative response of blood lymphocytes - MTT assay}

Mitogenic response of blood lymphocytes was determined using the MTT colorimetric assay [13]. Cells were suspended in RPMI 1640 growth medium containing mitogens - concanavalin A (ConA, Sigma-Aldrich) at a concentration of $5 \mu \mathrm{g} \mathrm{ml}^{-1}$ as a T-cell mitogen or lipopolysaccharide from Escherichia coli (LPS, Sigma-Aldrich) at concentration of $10 \mu \mathrm{g} \mathrm{ml}^{-1}$ as a B-cell mitogen and 100 $\mu \mathrm{l}$ of the suspension was added to each well of microtiter plates. The mixture was incubated for $72 \mathrm{~h}$. After incubation, $25 \mu \mathrm{l}$ of the solution containing $7 \mathrm{mg} \mathrm{ml}^{-1}$ of MTT (3-[4,5-dimethylthiazoly-2-yl]-2,5-diphenyltetrazolium bromide, Sigma-Aldrich) in PBS were added and the plate was incubated for the next $4 \mathrm{~h}$. The supernatant was removed and $100 \mu \mathrm{l}$ of DMSO was added to each well. The optical density was measured in a Sunrise absorbance reader (Tecan, Austria) at a wavelength of $570 \mathrm{~nm}$ with $640 \mathrm{~nm}$ as a reference wavelength. Samples obtained from each animal were tested in triplicate. The results of the proliferation assay were expressed as a stimulation index (SI), which was calculated by dividing the mean O.D. of stimulated cultures by the O.D. of the non-stimulated (control) cultures.

\section{Determination of blood granulocyte and monocyte phagocytic activity - Phagotest}

The blood granulocyte and monocyte phagocytic activity was measured in whole heparinized blood using a commercially available kit (Phagotest kit, Orpegen Pharma, Germany) according to manufacturer's instructions. In short, FITC-labeled opsonized E. coli bacteria were added to whole blood and incubated for $10 \mathrm{~min}$ at $37^{\circ} \mathrm{C}$ (experimental tube) or $0^{\circ} \mathrm{C}$ (negative control tube). After incubation, the reaction was stopped, erythrocytes were lysed and the DNA staining solution was added. Fluorescence of samples was measured using a FACSCanto II cytometer (Becton Dickinson Biosciences) in less than 60 min after the last reagent had been added. The data were acquired by FACSDiva version 6.1.3. software (BD Biosciences) and analyzed by FlowJo software (Tree Star Inc., Stanford, CA, USA). The Phagotest is performed with the involvement of fluorescein-stained $E$. coli bacteria which are phagocytized by the cells. The test determines the percentage of phagocytizing cells, granulocytes and monocytes separately, and their 
phagocytic activity, i.e. the number of bacteria absorbed by a single cell in terms of mean fluorescence intensity (MFI).

\section{Determination of oxidative burst activity of blood granulocytes and monocytes - Phagoburst}

Respiratory burst assay was performed using a commercially available kit (Phagoburst kit, Orpegen Pharma, Germany) according to manufacturer's instructions. Briefly, opsonized E. coli bacteria (experimental tube) or washing solution (negative control tube) were added to whole blood and incubated for $10 \mathrm{~min}$ at $37^{\circ} \mathrm{C}$. Following incubation, dihydrorhodamine (DHR 123) was added for $10 \mathrm{~min}$, erythrocytes were lysed and DNA staining solution was added. Dihydrorhodamine 123 becomes fluorescent when oxidized by reactive oxygen species, and its fluorescence was measured in less than $30 \mathrm{~min}$ after the last reagent had been added by flow cytometry, as described above. The test determines the percentage of active cells, as well as the respiratory burst intensity within a single cell in terms of mean fluorescence intensity (MFI).

\section{Statistical analysis}

Data were analysed statistically by one-way analysis of variance (ANOVA). Bonferroni's post test was used to determine differences between groups. Statistical evaluation of results was performed using GraphPadPrism software package.

\section{Results}

All the analyzed doses of KYNA affected the activity of leukocytes in the peripheral blood of mice, although the lowest one $(2.5 \mathrm{mg} / \mathrm{l})$ had the most profound influence in contrast to the highest one $(250 \mathrm{mg} / \mathrm{l})$, which produced the weakest effect. Besides, the effect of the lowest dose was in some respects different from the action produced by the two higher doses. It was only the influence of KYNA on the intensity of oxidative burst in granulocytes and monocytes that was similar irrespective of the applied dose (Table 1).

\section{Effect of KYNA administration on the proliferative activity of blood lymphocytes (MTT assay)}

The lowest KYNA dose stimulated the proliferative response of T lymphocytes $(p<0.05)$, after 7 and 28 days of administering the acid to the animals. The remaining doses did not affect significantly the activity of T cells. None of the assessed doses had any influence on the proliferative activity of B lymphocytes (Table 2).

\section{Effect of KYNA administration on the phagocytic activity of blood granulocytes and monocytes (Phagotest)}

A considerable effect of KYNA on the percentage of phagocytizing cells was observed after its prolonged administration, with the lowest dose causing a reverse effect to the one resulting from the application of the two higher doses. In response to the lowest dose given for the longest time (28 days), a significant decrease in the percentage of active cells, both among granulocytes $(p<0.05)$ and monocytes $(p<0.01)$, was observed. The two higher doses raised the

Table 1. Effect of oral administration of kynurenic acid on the activity of the peripheral blood leukocytes in mice: the summary

\begin{tabular}{|c|c|c|c|c|c|c|c|c|c|c|c|}
\hline \multirow{3}{*}{$\begin{array}{c}\text { KYNA } \\
\text { dose }\end{array}$} & \multirow{3}{*}{$\begin{array}{l}\text { Time } \\
\text { (days) }\end{array}$} & \multirow{2}{*}{\multicolumn{2}{|c|}{$\begin{array}{c}\text { Proliferative } \\
\text { response }\end{array}$}} & \multicolumn{4}{|c|}{ Phagocytosis } & \multicolumn{4}{|c|}{ Respiratory burst } \\
\hline & & & & \multicolumn{2}{|c|}{ active cells $(\%)$} & \multicolumn{2}{|c|}{ intensity (MFI) } & \multicolumn{2}{|c|}{ active cells (\%) } & \multicolumn{2}{|c|}{ intensity (MFI) } \\
\hline & & $\mathbf{T}$ cells & B cells & gran & mono & gran & mono & gran & mono & gran & mono \\
\hline \multirow{4}{*}{$2.5 \mathrm{mg} / 1$} & 3 & - & - & - & - & - & - & - & - & $\downarrow \downarrow$ & - \\
\hline & 7 & $\uparrow$ & - & - & - & - & 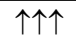 & - & 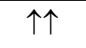 & $\downarrow \downarrow \downarrow$ & $\downarrow \downarrow \downarrow$ \\
\hline & 14 & - & - & - & - & $\uparrow$ & - & - & - & $\downarrow \downarrow \downarrow$ & - \\
\hline & 28 & $\uparrow$ & - & $\downarrow$ & $\downarrow \downarrow$ & - & - & $\downarrow$ & - & $\downarrow \downarrow \downarrow$ & $\downarrow \downarrow \downarrow$ \\
\hline \multirow{4}{*}{$25 \mathrm{mg} / \mathrm{l}$} & 3 & - & - & - & - & - & - & - & - & $\downarrow \downarrow$ & - \\
\hline & 7 & - & - & - & - & - & - & - & - & $\downarrow$ & - \\
\hline & 14 & - & - & $\uparrow$ & 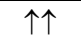 & $\uparrow$ & - & - & - & $\downarrow \downarrow$ & $\downarrow$ \\
\hline & 28 & - & - & - & - & - & - & - & - & $\downarrow \downarrow \downarrow$ & $\downarrow \downarrow \downarrow$ \\
\hline \multirow{4}{*}{$250 \mathrm{mg} / 1$} & 3 & - & - & - & - & - & - & - & - & - & - \\
\hline & 7 & - & - & - & - & - & $\uparrow \uparrow \uparrow$ & - & - & $\downarrow \downarrow \downarrow$ & $\downarrow \downarrow \downarrow$ \\
\hline & 14 & - & - & - & - & - & - & - & - & - & - \\
\hline & 28 & - & - & $\uparrow$ & - & - & - & - & - & - & - \\
\hline
\end{tabular}

MFI - mean fluorescence intensity, gran - granulocytes, mono - monocytes

$\uparrow-$ significant increase in comparison to the control group $(0), \downarrow$-significant decrease in comparison to the control group $(0)$ 
Table 2. Effect of dietary administration of kynurenic acid on the proliferative response of blood lymphocytes in mice (SI)

\begin{tabular}{|c|c|c|c|c|c|c|}
\hline \multirow{2}{*}{$\begin{array}{c}\text { Time } \\
\text { (days) }\end{array}$} & \multirow[t]{2}{*}{ Mitogen } & \multirow[t]{2}{*}{ Measure } & \multicolumn{4}{|c|}{ Group/dose of KYNA (mg/l) } \\
\hline & & & 0 (control) & 2.5 & 25 & 250 \\
\hline \multirow{4}{*}{3} & \multirow[t]{2}{*}{ ConA } & M & 1.188 & 1.408 & 1.245 & 1.132 \\
\hline & & SD & 0.165 & 0.188 & 0.209 & 0.117 \\
\hline & \multirow[t]{2}{*}{ LPS } & M & 2.003 & 1.723 & 1.879 & 1.907 \\
\hline & & SD & 0.187 & 0.219 & 0.349 & 0.146 \\
\hline \multirow{4}{*}{7} & \multirow[t]{2}{*}{ ConA } & M & 1.32 & $1.701^{*}$ & 1.487 & 1.337 \\
\hline & & SD & 0.151 & 0.218 & 0.232 & 0.152 \\
\hline & \multirow[t]{2}{*}{ LPS } & M & 1.522 & 1.732 & 1.699 & 1.576 \\
\hline & & SD & 0.182 & 0.264 & 0.204 & 0.139 \\
\hline \multirow{4}{*}{14} & \multirow[t]{2}{*}{ ConA } & M & 1.147 & 1.194 & 1.301 & 1.1023 \\
\hline & & SD & 0.147 & 0.17 & 0.234 & 0.096 \\
\hline & \multirow[t]{2}{*}{ LPS } & M & 1.415 & 1.441 & 1.349 & 1.505 \\
\hline & & SD & 0.255 & 0.268 & 0.242 & 0.206 \\
\hline \multirow{4}{*}{28} & \multirow[t]{2}{*}{ ConA } & $M$ & 1.203 & $1.547^{*}$ & 1.218 & 1.243 \\
\hline & & SD & 0.143 & 0.199 & 0.193 & 0.198 \\
\hline & \multirow[t]{2}{*}{ LPS } & M & 1.681 & 1.811 & 1.691 & 1.738 \\
\hline & & SD & 0.231 & 0.287 & 0.247 & 0.209 \\
\hline
\end{tabular}

SI - stimulation index, ConA - concanavalin A, LPS - lipopolysaccharide, M-mean, SD - standard deviation *statistically significant difference in comparison to the control group $(0)$ at $p<0.05$

Table 3. Effect of dietary administration of kynurenic acid on the percentage of phagocytizing cells in the peripheral blood of mice $(\%)$

\begin{tabular}{|c|c|c|c|c|c|c|}
\hline \multirow{2}{*}{$\begin{array}{c}\text { Time } \\
\text { (days) }\end{array}$} & \multirow[t]{2}{*}{ Cell type } & \multirow[t]{2}{*}{ Measure } & \multicolumn{4}{|c|}{ Group/dose of KYNA (mg/l) } \\
\hline & & & 0 (control) & 2.5 & 25 & 250 \\
\hline \multirow{4}{*}{3} & granulocytes & M & 79.9 & 75.94 & 75.22 & 77.16 \\
\hline & & SD & 5.138 & 5.663 & 7.29191 & 11.803 \\
\hline & monocytes & M & 34.56 & 23.54 & 29.04 & 32.6 \\
\hline & & SD & 6.357 & 7.132 & 10.902 & 10.207 \\
\hline \multirow{4}{*}{7} & granulocytes & M & 79.44 & 63.428 & 63.71 & 65.584 \\
\hline & & SD & 11.942 & 4.72 & 17.312 & 6.161 \\
\hline & monocytes & M & 25.556 & 14.818 & 17.188 & 19.666 \\
\hline & & SD & 8.95 & 2.425 & 7.221 & 8.603 \\
\hline \multirow{4}{*}{14} & granulocytes & M & 65.62 & 75.7 & $83.72 *$ & 74.82 \\
\hline & & SD & 9.953 & 6.193 & 11.232 & 7.872 \\
\hline & monocytes & M & 25.98 & 26 & $42.14 * *$ & 30.08 \\
\hline & & SD & 3.413 & 3.391 & 6.727 & 6.923 \\
\hline \multirow{4}{*}{28} & granulocytes & M & 77.92 & $62 *$ & 80.96 & $94.2 *$ \\
\hline & & SD & 9.694 & 10.401 & 1.524 & 2.371 \\
\hline & monocytes & M & 44.62 & $23.16^{* *}$ & 46.48 & 54.65 \\
\hline & & SD & 12.592 & 4.286 & 6.186 & 6.81 \\
\hline
\end{tabular}

$M$ - mean, $S D$ - standard deviation

*statistically significant difference in comparison to the control group $(0)$ at $p<0.05$,

** statistically significant difference in comparison to the control group $(0)$ at $p<0.01$ 
Table 4. Effect of dietary administration of kynurenic acid on the phagocytosis intensity in mice (MFI)

\begin{tabular}{|c|c|c|c|c|c|c|}
\hline \multirow{2}{*}{$\begin{array}{c}\text { Time } \\
\text { (days) }\end{array}$} & \multirow[t]{2}{*}{ Cell type } & \multirow[t]{2}{*}{ Measure } & \multicolumn{4}{|c|}{ Group/dose of KYNA (mg/l) } \\
\hline & & & 0 (control) & 2.5 & 25 & 250 \\
\hline \multirow[t]{4}{*}{3} & granulocytes & M & 12020.8 & 10157.2 & 10693.2 & 14000 \\
\hline & & SD & 1540.248 & 3383.947 & 2848.295 & 3629.738 \\
\hline & monocytes & M & 5199.8 & 5515.2 & 6473.8 & 5937.6 \\
\hline & & SD & 534.424 & 992.792 & 1254.748 & 949.627 \\
\hline \multirow[t]{4}{*}{7} & granulocytes & M & 6648.292 & 9509.088 & 5982.074 & 8998.966 \\
\hline & & SD & 1379.286 & 2227.11 & 892.843 & 2475.746 \\
\hline & monocytes & M & 1919.042 & $4584.336^{* * *}$ & 1989.32 & $4994.036^{* * * *}$ \\
\hline & & $\mathrm{SD}$ & 219.827 & 766.232 & 176.612 & 715.436 \\
\hline \multirow[t]{4}{*}{14} & granulocytes & M & 7899.2 & $13500^{*}$ & $14240 *$ & 7865.6 \\
\hline & & SD & 1361.969 & 3898.076 & 3134.167 & 1447.993 \\
\hline & monocytes & M & 4926 & 5700.4 & 6456 & 5510 \\
\hline & & SD & 870.029 & 782.378 & 1278.917 & 1577.983 \\
\hline \multirow[t]{4}{*}{28} & granulocytes & M & 11006.6 & 17320 & 11239 & 17275 \\
\hline & & SD & 3450.074 & 3287.4 & 1102.772 & 4675.735 \\
\hline & monocytes & M & 5928 & 7554 & 6080 & 6506.75 \\
\hline & & SD & 1574.729 & 2157.367 & 622.437 & 1624.163 \\
\hline
\end{tabular}

$M$ - mean, SD - standard deviation

*statistically significant difference in comparison to the control group $(0)$ at $p<0.05$

$* * *$ statistically significant difference in comparison to the control group $(0)$ at $p<0.001$

Table 5. Effect of dietary administration of kynurenic acid on the percentage of blood phagocytes subjected to oxidative burst after Escherichia coli stimulation in mice (\%)

\begin{tabular}{|c|c|c|c|c|c|c|}
\hline \multirow{2}{*}{$\begin{array}{c}\text { Time } \\
\text { (days) }\end{array}$} & \multirow[t]{2}{*}{ Cell type } & \multirow[t]{2}{*}{ Measure } & \multicolumn{4}{|c|}{ Group/dose of KYNA (mg/l) } \\
\hline & & & 0 (control) & 2.5 & 25 & 250 \\
\hline \multirow[t]{4}{*}{3} & granulocytes & M & 76.92 & 60.2 & 76.42 & 85.2 \\
\hline & & SD & 9.579 & 25.261 & 4.204 & 11.443 \\
\hline & monocytes & M & 23.86 & 31.34 & 21.5 & 35.6 \\
\hline & & SD & 8.162 & 12.449 & 8.379 & 9.228 \\
\hline \multirow[t]{4}{*}{7} & granulocytes & M & 58.73 & 39.024 & 54.438 & 43.464 \\
\hline & & SD & 5.671 & 24.145 & 4.639 & 16.39 \\
\hline & monocytes & M & 18.766 & $43.096^{* *}$ & 25.46 & 26.024 \\
\hline & & SD & 3.813 & 12.758 & 3.271 & 13.511 \\
\hline \multirow[t]{4}{*}{14} & granulocytes & M & 39.86 & 18.052 & 30.02 & 44.86 \\
\hline & & SD & 22.149 & 11.041 & 23.504 & 15.587 \\
\hline & monocytes & M & 23.614 & 28.032 & 18.684 & 39.7 \\
\hline & & SD & 18.229 & 18.369 & 18.123 & 16.323 \\
\hline \multirow[t]{4}{*}{28} & granulocytes & M & 45.7 & $18.733^{*}$ & 34.12 & 46.375 \\
\hline & & SD & 13.573 & 3.436 & 11.704 & 17.115 \\
\hline & monocytes & M & 15.82 & 16.957 & 22.012 & 21.355 \\
\hline & & SD & 6.592 & 11.246 & 11.394 & 10.52 \\
\hline
\end{tabular}

$M-$ mean, $S D-$ standard deviation

*statistically significant difference in comparison to the control group $(0)$ at $p<0.05$

$* *$ statistically significant difference in comparison to the control group $(0)$ at $p<0.01$ 
Table 6. Effect of dietary administration of kynurenic acid on the oxidative burst intensity after Escherichia coli stimulation in mice (MFI)

\begin{tabular}{|c|c|c|c|c|c|c|}
\hline \multirow{2}{*}{$\begin{array}{l}\text { Time } \\
\text { (days) }\end{array}$} & \multirow[t]{2}{*}{ Cell type } & \multirow[t]{2}{*}{ Measure } & \multicolumn{4}{|c|}{ Group/dose of KYNA (mg/l) } \\
\hline & & & 0 (control) & 2.5 & 25 & 250 \\
\hline \multirow[t]{4}{*}{3} & granulocytes & M & 2639.2 & $1555.4 * *$ & $1741.6^{* *}$ & 3068.5 \\
\hline & & $\mathrm{SD}$ & 467.449 & 248.335 & 39.272 & 586.211 \\
\hline & monocytes & M & 1974.8 & 1490.8 & 1656.8 & 1928.75 \\
\hline & & SD & 351.524 & 90.48 & 78.42 & 496.49 \\
\hline \multirow[t]{4}{*}{7} & granulocytes & M & 4511.01 & $2135.264 * * *$ & $3792.964 *$ & $2255.47 * * *$ \\
\hline & & $\mathrm{SD}$ & 459.733 & 206.387 & 448.683 & 172.315 \\
\hline & monocytes & M & 5235.65 & $1578.478^{* * *}$ & 4459.92 & $1606.02^{* * *}$ \\
\hline & & SD & 998.685 & 81.338 & 371.868 & 133.92 \\
\hline \multirow[t]{4}{*}{14} & granulocytes & M & 1998 & $1494.2 * * *$ & $1741.6^{* * *}$ & 1918.2 \\
\hline & & SD & 88.913 & 77.857 & 134.949 & 91.459 \\
\hline & monocytes & M & 1982.4 & 1557 & $1491.6^{*}$ & 1979.6 \\
\hline & & SD & 65.851 & 423.655 & 265.439 & 41.555 \\
\hline \multirow[t]{4}{*}{28} & granulocytes & M & 3471.2 & $2124 * * *$ & $2181.4^{* * * *}$ & 3352 \\
\hline & & SD & 246.133 & 146.277 & 84.636 & 303.131 \\
\hline & monocytes & M & 3522 & $1928.333 * * *$ & $2281.6^{* * * *}$ & 3428.5 \\
\hline & & SD & 257.287 & 87.763 & 723.992 & 193.435 \\
\hline
\end{tabular}

MFI - mean fluorescence intensity, $M$ - mean, $S D$ - standard deviation

*statistically significant difference in comparison to the control group $(0)$ at $p<0.05$

** statistically significant difference in comparison to the control group $(0)$ at $p<0.01$

$* * *$ statistically significant difference in comparison to the control group $(0)$ at $p<0.001$

percentage of phagocytizing granulocytes - the medium dose $(25 \mathrm{mg} / \mathrm{l})$ after 14-day administration $(p<0.05)$ and the highest dose after 28 days $(p<0.05)$. In addition, the medium dose, after 14 days of administration, caused an increase in the percentage of active monocytes $(p<0.01)$ (Table 3 ).

The influence of KYNA on the rate of phagocytosis, measured by an average fluorescence intensity of cells, was positive, irrespective of the applied dose. However, it occurred after a slightly shorter time of the administration of KYNA to animals. The lowest dose stimulated the ingestion of bacteria by monocytes after 7 days $(p<0.001)$ and by granulocytes after 14 days of administration $(p<0.05)$. The medium dose intensified phagocytosis only in granulocytes after 14 days of administration $(p<0.05)$, whereas the highest dose resulted in more intensive phagocytosis only in monocytes after 7-day administration $(p<0.001)$ (Table 4).

\section{Influence of KYNA administration on the oxidative burst activity of blood granulocytes and monocytes (Phagoburst)}

It was only the lowest dose of KYNA that had an effect on the percentage of cells subjected to oxidative burst after bacterial stimulation, by increasing substantially the number of active monocytes after 7 days $(p<0.01)$ and de- pressing the count of active granulocytes after the longest administration period $(p<0.05)$. The two higher doses did not have a significant influence on this parameter, regardless of the duration of their administration (Table 5).

Irrespective of the applied dose, KYNA significantly depressed the intensity of oxidative burst in cells, and granulocytes proved to be most sensitive to KYNA. The two lower KYNA doses caused a significant effect on granulocytes starting from day 3 of administration, and this influence lasted until the experiment was terminated. Regarding the highest dose of KYNA, a decrease in the intensity of respiratory burst in granulocytes was observed only after 7 days of administration $(p<0.001)$. A significant decline in the analyzed parameter in monocytes was noticed after 7 and 28 days of the administration of the lowest dose $p<0.001)$, after $14(p<0.05)$ and $28(p<$ $0.001)$ days of giving the medium dose and only after 7 days $(p<0.001)$ of giving the highest dose (Table 6 ).

\section{Discussion}

In view of the literature data, the stimulation of T lymphocyte proliferation observed in the present experiment in response to the lowest KYNA dose may seem a rather unexpected result. As mentioned in the introduction, both 
the IDO and kynurenine pathway stimulation alone and some of this pathway metabolites produce an anti-proliferative effect on T cells. In the case of such kynurenines as L-kynurenine, 3-hydroxykynurenine and 3-hydroxyanthranilic acid this effect is most probably due to the cytotoxic influence of their high concentrations [4]. However, not all IDO metabolites act in the same manner. Terness et al. [4] proved the lack of influence of anthranilic acid and quinolinic acid on T cells, and in a study by Kudo et al. [1], KYNA, rather than inhibiting the proliferation of the peripheral blood mononuclear leukocytes, caused their slight stimulation (not significant statistically). Kynurenine as such, in investigations conducted by several researchers, produced various effects: leaving T cells unaffected, or else producing pro-apoptotic and anti-proliferative effects, but such divergent results may have originated from differences between experimental models [1, 3, 4]. Also, our previous experiment on rainbow trout given kynurenic acid in feed revealed a slightly different way in which KYNA affected proliferation of lymphocytes from the one detected herein. In fish, similar to mice, the proliferation of $\mathrm{T}$ cells was stimulated by the lowest dose of the acid $(2.5 \mathrm{mg} /$ $\mathrm{kg}$ feed) after 28-day administration, but the highest dose $(250 \mathrm{mg} / \mathrm{kg}$ feed) after the shortest administration period (7 days) significantly inhibited the proliferation of both $\mathrm{T}$ and B cells [14]. An elevated level of KYNA, which is not toxic, could have nonetheless affected lymphocytes by promoting apoptosis, as some other kynurenines do [4, 8]. Thus, it appears that kynurenic acid can produce a variety of effects on lymphocytes, depending on its dose, duration of its administration, administration route or, finally, the species of animals which are given such supplementation. The mechanism of action may be different for KYNA and for other kynurenines, which could be due to the fact that the GPR35 receptor on the surface of immune cells is selectively activated by KYNA but not by other kynurenines.

Besides, it has been demonstrated that KYNA influences the activity of phagocytizing cells through the GPR35 receptor. The expression of this receptor is much stronger on monocytes, neutrophils, dendritic cells and T cells than on B lymphocytes, iNKTs, eosinophils and basophils [8]. The activation of the receptor by KYNA induces an anti-inflammatory action through the inhibition of the synthesis of early (TNF- $\alpha$, IFN- $\gamma$ ) and late (HMGB1) pro-inflammatory cytokines by mononuclear cells, including monocytes and macrophages [2, 3, 15, 16]. Also, KYNA lowered the secretion of HNP1-3 $\alpha$-defensin in granulocytes, the substance which serves as an indicator of the activation of these cells [16]. It can therefore be supposed that KYNA inhibits the activity of phagocytizing cells. On the other hand, it has also been demonstrated that KYNA stimulates adhesion of monocytes and neutrophils to the vascular endothelium, which is an important element of the activation and migration of phagocytizing cells from the bloodstream to tissues. The positive influence of KYNA on this process suggests that the acid can play a part of chemokine in an early stage of the activation of leukocytes and its effect on phagocytizing cells might include the early activation phase and late anti-inflammatory phase [17]. The above observations can explain the unequivocal influence of KYNA on the peripheral blood phagocytizing cells in mice, shown herein. This influence changed depending on the dose of KYNA, its administration period and the type of examined cells, with the stimulating influence on some of the examined parameters more typically noticed after shorter KYNA administration periods.

The only of the analyzed parameters which all the tested doses of the acid affected in a similar fashion throughout most of the experiment was the intensity of oxidative burst. Both in granulocytes and in monocytes, a decrease in the oxidative metabolism of cells occurred, and this event was probably connected with the antioxidant properties of KYNA. The literature data prove that some of the kynurenic pathway metabolites, including kynurenic acid, are redox active substances. Antioxidant characteristics of KYNA have been verified both in in vitro studies and on an animal model. In non-biological systems, KYNA turned out to be a potent ROS (reactive oxygen species) scavenger, active towards the hydroxyl radical $(\bullet \mathrm{OH})$, superoxide anion $\left(\mathrm{O}_{2}^{-}\right)$and peroxynitrite anion $\left(\mathrm{ONOO}^{-}\right)$. Kynurenic acid was proved to be ten-fold more active towards the superoxide anion than a very important endogenous antioxidant such as GSH. It has been demonstrated on biological models that lipid peroxidation, oxidative protein degradation and ROS formation were depressed in the presence of KYNA [18]. A decreased synthesis of ROS may have been an effect of KYNA acting on the NO level and activity of the enzymes involved in this process. Kaszaki et al. [9] showed a depressed activity of XO (xanthine oxidase) due to KYNA under in vitro conditions, and a reduction of the activity of XOR (xanthine oxidoreductase, main source of the mucosal superoxide radical) in intestines of dogs with mechanical colon obstruction caused by exogenous kynurenic acid. Moreover, both in dogs with colon obstruction and in mice subjected to endotoxemia, KYNA caused a significant decrease in the NO level in blood serum, which enables us to perceive it as a potential endogenous anti-inflammatory factor, particularly helpful in combating systemic inflammations [7, 9]. It is so because NO affects the recruitment of leukocytes, leads to production of reactive oxygen and nitroso species, and is one of the factors responsible for death due to septic shock.

Both nitrogen oxide and ROS, whose levels in the quoted research were affected by KYNA, are key substances engaged in the process of oxidative burst, examined in the present study. The oxygen-dependent mechanisms of eliminating microorganisms by phagocytes are an extremely important aspect of the non-specific (innate) immune response of an organism to infectious agents, but overproduction of ROS by phagocytizing cells leads to 
some damage of tissues around the site of inflammation and plays a role in the pathogenesis of such diseases as emphysema, acute respiratory distress syndrome, atherosclerosis, malignancy and rheumatoid arthritis [19]. Thus, kynurenic acid may find applications as an immuno-modulating agent able to correct an excessive or inadequate response of phagocytizing cells, protecting the organism from oxidative stress. In this research, the strongest inhibitory effect, both on ingestion of bacteria and oxidative burst, was generated by the lowest dose of KYNA after the longest administration period, although a decreased rate of respiratory burst was observed already on the third day of administration of the acid. The effect appeared in healthy animals, hence a choice of a dose as well as a route and duration of the administration of kynurenic acid to diseased patients requires further and broader research.

Authors declare no conflict of interest.

The research funded from the Polish National Science Centre grant no. NN 308578540.

\section{References}

1. Kudo Y, Boyd CA, Sargent IL, Redman CW (2001): Tryptophan degradation by human placental indoleamine 2,3-dioxygenase regulates lymphocyte proliferation. J Physiol 535: 207-215.

2. Maes M, Mihaylova I, Ruyter MD, et al. (2007): The immune effects of TRYCATs (tryptophan catabolites along the IDO pathway): relevance for depression- and other conditions characterized by tryptophan depletion induced by inflammation. Neuro Endocrinol Lett 28: 826-831.

3. Mándi Y, Vécsei L (2012): The kynurenine system and immunoregulation. J Neural Transm 119: 197-209.

4. Terness P, Bauer TM, Röse L, et al. (2002): Inhibition of allogenic $\mathrm{T}$ cell proliferation by indoleamine 2,3-dioxygenase-expressing dendritic cells: mediation of suppression by tryptophan metabolites. J Exp Med 196: 447-457.

5. Chen Y, Guillemin GJ (2009): Kynurenine pathway metabolites in humans: disease and healthy states. Int J Tryptophan Res 2: 1-19.

6. Wang J, Simonavicius N, Wu X, et al. (2006): Kynurenic acid as a ligand for orphan $\mathrm{G}$ protein-coupled receptor GPR35. J Biol Chem 281: 22021-22028.

7. Moroni F, Fossati S, Chiarugi A, Cozzi A (2007): Kynurenic acid actions in brain and periphery. Int Congr Ser 1304: 305-313.

8. Fallarini S, Magliulo L, Paoletti T, et al. (2010): Expression of functional GPR35 in human iNKT cells. Biochem Biophys Res Commun 398: 420-425.

9. Kaszaki J, Palásthy Z, Érczes D, et al. (2008): Kynurenic acid inhibits intestinal hypermotility and xanthine oxidase activity during experimental colon obstruction in dogs. Neurogastroenterol Motil 20: 53-62.

10. Paluszkiewicz P, Zgrajka W, Saran T, et al. (2009): High concentration of kynurenic acid in bile and pancreatic juice. Amino Acids 37: 637-641.
11. Wejksza K, Rzeski W, Turski WA (2009): Kynurenic acid protects against the homocysteine-induced impairment of endothelial cells. Pharmacol Rep 61: 751-756.

12. Turski MP, Turska M, Zgrajka W, et al. (2009): Presence of kynurenic acid in food and honeybee products. Amino Acids 36: 75-80.

13. Mosmann T (1983): Rapid colorimetric assay for cellular growth and survival: application to proliferation and cytotoxicity assays. J Immunol Methods 65: 55-63.

14. Małaczewska J, Siwicki AK, Wójcik R, et al. (2013): Effect of dietary administration of kynurenic acid on the activity of splenocytes of the rainbow trout (Oncorhynchus mykiss). Cent Eur J Immunol 38: 475-479.

15. Kiank C, Zeden JP, Drude S, et al. (2010): Psychologial stress-induced, IDO1-dependent tryptophan catabolism: implications on immunosuppression in mice and humans. PLoS One 5: e11825.

16. Tiszlavicz Z, Németh B, Fülöp F, et al. (2011): Different inhibitory effects of kynurenic acid and a novel kynurenic acid analogue on tumour necrosis factor- $\alpha$ (TNF- $\alpha$ ) production by mononuclear cells, HMGB 1 production by monocytes and HNP1-3 secretion by neutrophils. Naunyn-Schmied Arch Pharmacol 383: 447-455.

17. Barth MC, Ahluwalia N, Anderson TJT, et al. (2009): Kynurenic acid triggers firm arrest of leukocytes to vascular endothelium under flow conditions. J Biol Chem 284: 1918919195.

18. Lugo-Huitron R, Blanco-Ayala T, Ugalde-Muńiz P, et al. (2011): On the antioxidant properties of kynurenic acid: free radical scavening activity and inhibition of oxidative stress. Neurotoxicol Teratol 33: 538-547.

19. Babior BM (2000): Phagocytes and oxidative stress. Am J Med 109: 33-44. 